\title{
Business Process Outsourcing(BPO): Emerging Scenario and Strategic Options for IT-enabled Services
}

\author{
K Ramachandran and Sudhir Voleti
}

Executive Summary

KEY WORDS

\section{Business Process Outsourcing}

IT-enabled Services

Theory of the Firm

Sub-contracting Services
The paradigm shift that the Internet has brought about in communication has opened up a plethora of opportunities for outsourcing business processes (BPO) across continents. Success lessons in manufacturing sub-contracting are found to be relevant for understanding the logic of BPO. Outsourcing involves transferring certain value contributing activities or processes to another firm to save costs and for the principal to focus on its areas of key competence. The possibilities of disaggregating value elements for the purpose of creating value in them at the sub-contractors' premises and final aggregation and synthesis at the parent organization are determined by the nature of industry, limitations of coordination and control, product maturity, and level of inter-firm competition.

IT-enabled services (ITES) includes services that can be outsourced using the powers of IT; the extent to which this is possible depends on the industry, location, time, costs, and managerial perception of the risks involved. The Internet has facilitated execution of several activities, previously done within geographical proximity to the firm, from remote low-labour cost locations, drawing both transaction cost and production cost efficiencies.

Some of the factors that come in the way of parents setting up their own operations in India and have significant implications for the growth trajectory of Indian BPOs are:

$>$ direct cost of operations and scale economies

$>$ long-term assessment of India as a low cost centre

$>$ cost-benefit assessment of own vs rented

$>$ possible loss of control over their transactions and confidentiality and security of the data if an outsider handles them

$>$ brand implications of perceived drop in quality

$>$ robustness of existing systems and processes.

Many BPO firms do not seem to realize the possible exit barriers and strategies to manage exit, if necessary. What happened in the dot com era can very well happen in the BPO space also unless care is taken to manage this rapid growth while retaining productivity and quality.

Two key capabilities required for success in ITES space are: capabilities to understand customer needs in the specific domains and acquiring business (BD capabilities) and capabilities to execute them efficiently (Ops capabilities). ITES firms are likely to bifurcate their firm into two parts based on these two critical success factors.

The successful segregation of value elements in a number of processes has enabled value configuration in as many ways as required by customers, both in the case of product and service components of customer value. The current trend in outsourcing will go up when such analysis-synthesis becomes a routine. This will be accelerated also because the capabilities required to do so depend not only on technical skills and knowledge in a domain but also strong process capabilities.

The trend of outsourcing is likely to continue to grow in the future despite temporary political protests because of the robust arguments outsourcing finds for itself in the economics literature, both in terms of transaction and production cost advantages. Subcontractors need robust systems and processes along with adequate domain knowledge and assured physical infrastructure for this to happen.

In any case, the Indian BPO firms have to consistently prove their capabilities to deliver and create near indispensable situation for the parent to survive without them. This will not only involve growing technical and domain expertise, but also refinement in systems and practices, while keeping costs under control. In essence, BPO firms have to manage their consolidation and growth challenges simultaneously. 
$\mathrm{T}$ The paradigm shift in the possibilities of communication that the Internet and the telecommunications revolution has brought about has opened up a plethora of opportunities in outsourcing business processes across continents. What began as a rivulet a few years ago has already become a river of gigantic proportions, creating economic and political waves of mammoth proportions in countries such as the US and India. The canvas of possibilities of outsourcing has changed its colours from low cost call centres to knowledge intensive value added services.

Business Process Outsourcing (BPO) is a boon for a developing country such as India but, of late, it has become a political issue for the US with major economic implications. This is particularly so with continued recession and job losses in the midst of the Presidential elections in the US due later this year. While the debate on the economic rationale is almost settled, the threat of a series of legislations curbing outsourcing is very real, and the question that bothers everyone is the longterm implications of such outsourcing of business processes on the economies of the firms and the countries involved. For the US, the worry is greater because the service industry, which pulled the economy out of the woods after losing a lot of manufacturing to Japan and later China, is in the eye of the current storm and the most affected by it. Several agencies (Armour and Kessler, 2003) have estimated that job losses due to outsourcing by firms in the US would go up from over 100,000 in 2000 to nearly 600,000 in 2005, including both IT-related and other skill-based jobs. (If services also go, what could the US do is a moot question!). The implication is that more value added jobs are likely to be increasingly outsourced as the BPO model stabilizes and transaction cost efficiencies are recognized.

In this paper, we explain why BPO in general and IT-enabled services (ITES) in particular is here to stay based on sound conceptual reasoning, disregarding the political arguments involved. We will also discuss the evolving growth trajectories for organizations to follow in the context of the emerging scenario based on three brief cases of ITES firms.

\section{WHY OUTSOURCING?}

In an interdependent socio-economic structure, outsourcing is natural. The extent to which it would happen or the value links that need to be integrated in different degrees varies (Rumelt, 1974; Barreyre, 1988; Prahalad and Hamel, 1994; Porter, 1980, 1996). Modern industrial history called this sub-contracting, primarily in the manufacturing context.

Outsourcing involves transferring certain value contributing activities, processes and/or services to the premises of one's own or an agent primarily to save costs and/or for the principal to increasingly focus on its areas of key competence. The structure of this principal-agent relationship varies from loose networks to neatly packed pyramidal structures. While in the US, each transaction is generally independent and individually negotiated, the Japanese system broadly depends a lot on mutual trust and learning developed over a period of time. In the former, up-front quality inspection and threat of rejection are part of the relationship; in the latter, the incentive to furnish high quality is governed by an implicit promise of contract renewals (Taylor and Wiggins, 1997).

The possibilities of disaggregating value elements for the purpose of creating value in them at the subcontractors' premises and final aggregation and synthesis at the parent organization are determined by the nature of industry, limitations of coordination and control, product maturity, and level of inter-firm competition. An understanding of the evolution of the pyramidal type of Japanese sub-contracting system, horizontal value networks existing in industries such as the garment industry, and limitations of sub-contracting in service industries provide useful insights into the logic of BPO in the present context.

The Japanese sub-contracting system is widely discussed in the literature (Webster, Muhlemann and Alder, 2000; Gilbert, Young and O'Neal, 1994; Nishiguchi, 1994; Morris and Imrie, 1993; Schoenberger, 1982). Over the years, Japanese companies in electronics, automobiles, and machinery industries began involving their sub-contractors in joint design with their customers (Nishiguchi and Brookfield, 1997). Although many subcontractors did not create specific assets for particular firms (Miwa and Ramseyer, 2000), inter-firm trust and consultation grew. This is a reflection of not only trust in the sub-contractors' capabilities but a sign of the need for collaboration among the key input providers to build competitiveness for their ecosystem in the market place. In the manufacturing context, these possibilities were limited by physical proximities, regulatory restrictions, and economic limitations. (This has major implications for $\mathrm{BPO}$ models in the current context where cost, 
quality, and features are key dimensions of competition for the firms outsourcing as discussed later.) The process of globalization with breakdown of regulatory and communication barriers across countries has also generated many options for value creating elements. In an era of growing customization, such synthesis of insight and action are inevitable and the opportunities phenomenal.

The commercial potential for breaking up of territorial restrictions and the benefits of tapping enhanced value creation possibilities got reflected elsewhere too. Li-Fung (Magretta, 1998), Hong Kong's largest garment exporter, demonstrated the benefits of redefining the value creation process and developing robust information and control systems using the powers of IT. Through a series of ownership and relationship networks and control systems, Li-Fung demonstrated that the success of outsourcing outside geographical territories depended on identification of sub-contractors and existence of appropriate control systems. Evidences of sub-contracting of pure services such as security services, housekeeping, and the general model of franchise business, where outsourcing is at the delivery end of value chain, also offer great learning opportunities for the current discussion on BPO.

In all these value configurations, the objective is to offer greater value to customers at lower costs. The basic challenge is in assuring fulfilment of quality parameters, particularly when both production and consumption take place simultaneously as in a service business. It is all the more high when the parent firm is located geographically away from the sub-contracting service provider and the consumer is in yet another totally different geo-cultural context, effectively denying possibilities of exercising any close physical control or coordination. Consequently, the growth in sub-contracting and restructuring of manufacturing activities had little impact on the way service businesses were configured. Since services, by nature, are produced and consumed simultaneously, it was difficult to reconfigure many service value chains. Besides, the behaviour of a number of input variables such as local supply of relevant infrastructure, work culture, and skill set of staff has been beyond the control of either the subcontractor or its parent firm. However, the logic of outsourcing is so powerful that the trend of outsourcing is likely to continue to grow in future. Since organization of economic activities is based on the principles of transaction costs and production costs, it is unlikely that the trend will be reversed. This is explained in the following section.

\section{Transaction Cost Efficiency}

The rationale for the existence of the firm as delineated in the theory of the firm is primarily based on considerations of transaction cost and production cost efficiencies (Williamson, 1971, 1973; Alchian and Demsetz, 1972). The transaction cost approach to the theory of the firm hypothesizes that firms are organizational innovations born out of the costs involved in market transacting in order to reduce those costs. A 'transaction' here represents the transfer of a good or service across a technologically separable interface (Williamson, 1971, 1973). The boundary between firms is an example of just such an interface. The definition may also extend to different sub-organizational boundaries delineated by geography (e.g., the North American arm of a firm vis-à-vis the European arm), product specialization (e.g., GE's medical equipment division vis-à-vis GE Capital) or ownership (e.g., Suzuki Corporation transacting with Maruti Udyog). It will be efficient to substitute firms for markets only if the costs of transacting across markets become larger than the costs of managing the firm. Coase (1937) has argued that a firm will substitute market transactions as long as management costs are less than transaction costs.

Thanks to the advances made in Information Technology in the past two decades including the arrival of the Internet, it is now possible to execute several activities previously done within geographical proximity to the firm, and often inside firm boundaries, from remote low-labour cost locations. This concept of remotely executing tasks is the phenomenon of $\mathrm{BPO}$, a part of which is called ITES, which has tremendous implications for transaction cost efficiencies. Tables 1(a) and 1 (b) show that relative cost benefits of outsourcing from India are very attractive for countries such as the US.

\section{Production Cost Efficiency}

The concept of production cost efficiency posits that production by a team is the distinguishing characteristic of the firm (Alchian and Demsetz, 1972) and the team continues in existence only as long as the team output is sufficiently greater than the sum of the output under independent production to justify the costs of organizing and monitoring team members. Hence, production cost 
Table 1 (a): Comparison of Operating Costs of India as Percentage of US Costs

\begin{tabular}{lrrc}
\hline $\begin{array}{l}\text { US\$ Cost per } \\
\text { Full Time Employee }\end{array}$ & USA & India & \begin{tabular}{c} 
India $\begin{array}{c}\text { as } \% \text { of } \\
\text { US Costs }\end{array}$ \\
\hline Personnel
\end{tabular} \\
G\&A expense & 42,927 & 6,179 & 14 \\
Telecom & 8,571 & 1,000 & 12 \\
Property rentals & 1,500 & 2,328 & 155 \\
Depreciation & 2,600 & 847 & 33 \\
Total Expenses & 3,000 & 1,500 & 50 \\
\hline
\end{tabular}

Source: Industry sources, Merill Lynch, 2003 (from the NASSCOM Strategic Review): (http://www.bpoindia.org/knowledgeBase).

Table 1 (b): Industry Size in India

\begin{tabular}{lcc}
\hline \multicolumn{1}{c}{ Growth Trend of the Outsourcing Industry } \\
\cline { 2 - 3 } Service Area & \multicolumn{2}{c}{ 2002-03 } \\
\cline { 2 - 3 } & Employment & Revenue (in \$m) \\
\hline Customer care & 65,000 & 810 \\
Finance & 24,000 & 510 \\
HR & 2,100 & 45 \\
Payment service & 11,000 & 210 \\
Administration & 25,000 & 310 \\
Content development & 44,000 & 465 \\
Total & $\mathbf{1 , 7 1 , 1 0 0}$ & $\mathbf{2 , 3 5 0}$ \\
\hline
\end{tabular}

Source: NASSCOM (http://www.bpoindia.org/knowledgeBase).

efficiencies will be greater when the extent of scale economies of management and production are also high (Weston, Chung and Hoag, 1990).

In general, an asset's productivity increases with its specialization to other inputs used in the production process. However, specialization also increases the risk of loss to the owner of the specialized asset if the other inputs are 'held up' or withdrawn. The perceived relative bargaining power of the owners of the specialized value links influence the decision to opt for the extent of outsourcing an organization would accept. At the same time, Klein, Crawford and Alchian (1978) propose that the greater the degree of asset specificity, the more likely that transactions would be carried out more efficiently within organizations. Whenever a resource is dependent on (or specialized to) the rest of the team, there is a temptation on the part of some contractors (or contracting parties) to hold up the dependent resource in order to expropriate its quasi-rent. This, of course, depends on the balance of demand and supply of resources available at any given point in time. Possible threats to BPOs from such a situation are low at present when the industry is growing rapidly. The wind can blow in the other direction too!

Input owners thus have incentives to make preinvestment arrangements to discourage rent-seeking and promote confidence in the joint use of assets. They will choose an organizational form that minimizes transaction costs. The greater the transaction costs relative to the value of the output unique to the joint use of resources, the more critical the search for an economizing form, particularly in competitive industries where cost economies are essential for firm survival. Long-term explicit contracts are one solution to the problem. Another is common ownership of the complementary assets that leads to relationships such as joint ventures, vertical or horizontal integration, and BuildOperate-Transfer (BOT) basis contracts. This is evident in the common facilities available at the software technology parks; experiences of common facility centres in the manufacturing sector support this argument.

Possibilities of deriving scale economies exist both at the stage of operations at the outsourcer's premises and also while mutually understanding the outsourcer's requirements by an outsourcee in the context of the particular business and its success. To be successful, firms need to possess two kinds of capabilities, viz., understanding customer needs and acquiring business and successfully executing using appropriate technical skills. While in a firm with a fully integrated value chain, both the execution capabilities for developing/acquiring business based on domain expertise and executing reside in the same firm, this is not so in all the firms in the BPO space, as discussed later. On the operations front, BPO service providers offer scale economies by spreading the fixed cost of setting up and maintaining facilities and infrastructure over several clients. This is true with captive BPO units also where different geographical units of the same firm make economic sense when each one of them fulfills efficient size considerations. This kind of scale economies is primarily a reflection of the firm's Operations Capabilities (Ops). Further, learning curve effects realize scale economies to management when one set of similar activities is outsourced to one service provider. We note that, in this case, the scale economies to management are realized by outsourcing to firms which have the required level of domain expertise to understand the outsourcer's requirements fully. Success on this count is a reflection of the overall Business Development Capabilities (BD) of the firm.

From the large body of extant literature on the imperative to outsource (Antonucci and Tucker, 1998), the following reasons come out very clearly as determi- 
nants of outsourcing:

- cost reduction

- core competence focus

- flexibility while retaining control

- competitive advantage through strategic outsourcing.

In essence, the logic of outsourcing of services is based on sound economic principles. Learnings from the experiences on the manufacturing front suggest that outsourcing will continue to happen within or across geographical boundaries.

\section{BPO AND ITES: THE LINK}

The rapid growth in ITES has often given an impression that it is quite independent of $\mathrm{BPO}$ which is not true. As the term suggests, ITES includes services that can be outsourced using the powers of IT. The extent to which IT can be leveraged varies under the influence of suitability to industry, location, time, costs, and managerial perception of the risks involved. As shown in Table 2, the processes that can be outsourced can be classified into IT-enabled and others. Similarly, all the organizational processes can be broadly grouped into three depending on the extent to which each is a core process, critical but non-core, and non-critical and noncore. The boom in ITES is primarily in customer care, followed by administration and banking, all at the lower end of an intellectual pyramid, but involving large number of people. However, the significant proportion of people involved in content development is an indicator of possible opportunities at the higher levels of the pyramid [Table 1(a)].

The primary resources for building execution capabilities are capital and technology apart from peoplebased resources. The building of execution capability requires investment in operations infrastructure which, in turn, heavily depends on the intended or planned size of operations in terms of scale. The scope for variation in the complexity of the task outsourced and level of

\section{Table 2: IT-enabled Services Possibilities}

\begin{tabular}{|c|c|}
\hline Nature of Activity & Possibilities for Outsourcing \\
\hline Core processes & $\begin{array}{l}\text { Key to firm success and strategic in nature } \\
\text { (e.g., R\&D) }\end{array}$ \\
\hline $\begin{array}{l}\text { Critical non-core } \\
\text { processes }\end{array}$ & $\begin{array}{l}\text { Important but not one of the differentiators } \\
\text { (e.g., supply chain management, accounting, } \\
\text { and HR administration) }\end{array}$ \\
\hline $\begin{array}{l}\text { Non-critical, non-core } \\
\text { processes }\end{array}$ & $\begin{array}{l}\text { Relatively less critical and can be mostly } \\
\text { outsourced (e.g., data analysis for routine } \\
\text { information and administration) }\end{array}$ \\
\hline
\end{tabular}

VIKALPA • VOLUME 29 •NO 1 • JANUARY - MARCH 2004 expertise required for execution is enormous, depending on the Functional Value Captured (FVC). For instance, Raman Roy, founder of Spectramind divided the teleworking pie into five slices in the ascending order of value (The Economist, 2001) as follows:

- Data entry and conversion which includes medical transcription.

- Rule-set processing in which a teleworker makes judgements based on a set of rules set by the customer.

- Problem solving in which a teleworker has more discretion; the rules here are fluid and less amenable to structuring than in the rule-set processing genre.

- Direct customer interaction in which the teleworker handles more elaborate interaction with the client's customers. Services here could include support and maintenance and payment collections.

- Expert 'knowledge services' which require specialists (with the help of a database).

'Teleworking' as described above is amenable to any definition of ITES involving remote processing services of information (data, voice, images, multimedia). The Economist (2001) described the above categorization as extendable to 'just any service that is deliverable over fibre-optic wire' which is intuitively understandable as well. The higher the FVC, the higher are the entry barriers. In the normal course, returns, market scope, and growth potential are higher for higher FVCs (Porter, 1985).

As mentioned earlier, many of the processes that could not be outsourced earlier are done so now thanks to the developments on the IT front globally and growing level of comfort parent firms have with BPO firms in countries such as India. It is relevant to note here that the relocation of business processes including ITES was initially intra-national, i.e., to low-cost locations within the same country, but significant breakthroughs in digitization technologies and data transmission with resultant savings in costs enabled development of this practice to travel across continents. Consequently, labour cost, skill availability, and infrastructure quality became the determinants for relocating services.

\section{THEORY OF THE FIRM AND ITES-BPO}

The implications of the theoretical discussion are already evident in the Indian BPO scene. The industry, particularly the ITES sector, has grown manifold. The number of BPO professionals (most of whom belong to 
ITES) has gone up from 42,000 in $1990-2000$ to 171,000 in 2002-03, according to NASSCOM (2004) which expects the industry to grow at over 50 percent in 2004-05. The benefits of this growth will mainly accrue to firms with specific resources and domain expertise while owners of more general resources choose pre-specified rewards.

To recall, we had defined $\mathrm{BD}$ as the capability to understand customer needs in the specific domain of activity and resultant managerial function of procuring business and maintaining client relationships for the firm. Ops, on the other hand, was defined as the execution-of-contract capability. Several firms in the Ops space have specialized assets creating barriers to exit from the industry, as opposed to BD which is much more flexible and mobile. For instance, creation of Ops facilities requires relatively large, upfront capital investments (US \$10,000 per seat in ITES call-centres in India). Besides the basic computing facilities, several special purpose equipments are required depending on the industry of focus such as telemarketing and attempting to dispose of the hardware (in order to, say, recoup a sour investment) is likely to yield low return in the IT hardware market.

The theory of the firm postulates that, in situations where specialized assets are dependent on inputs from general-resource owners, there is a tendency on the part of the general resource owners to try to expropriate more of the quasi-economic rent accruable to the specialized asset through the threat of hold up because of greater bargaining power. In the $\mathrm{BPO}$ scenario, entry level $\mathrm{BPO}$ employees, being plentifully available, would not be in a position to significantly indulge in rent-seeking behaviour. Even so, Ops employees can be considered as general resource input owners and the extremely high attrition rates in $\mathrm{BPO}$ companies in India also testify to the mobility of this general resource. Thus, owners of the Ops facilities are often the owners of the Ops function. However, since the basic facility available at any of the Ops firms can be treated as 'general purpose,' they have the freedom to switch from one contractor to another within the same industry. These facilities are standardized, and hence, create a situation of too many suppliers leading to falling prices and losing bargaining power.

We now examine whether there is any possibility, in theory, of expropriation by BD against Ops. The picture is muddled as most Ops facilities as well as the BD inputs are held in common ownership. We posit that this may be set to change. Captive BPO units with limited further outsourcing potential are coming under immense pricing pressure owing to their being cost centres and unable to spread fixed infrastructure costs across a wide range of customers if their capacities are not fully used. Third party Ops facilities, on the other hand, not only promise lower prices but also higher productivity (again measured in revenue per seat basis) because of their independence and allocation of resources and costs to different customers more economically. Thus, we posit that expropriation by BD may take the form of increased pricing pressure, the threat of moving business to other specialized assets available in the market, and more stringent contract fulfillment terms.

Ownership integration refers to the extent to which input providers of an asset also own the asset - with full equity ownership representing one end of the spectrum, joint ventures and minority equity stakes forming an intermediate level, and formal, arms-length contract-based transactions the other extreme of the ownership integration continuum. In low value activities, availability of more-or-less standardized Ops facilities for hire will make for a greater preponderance of arms-length contracts in such low value activities.

\section{FUTURE OF BPO}

\section{Current Debate}

The above discussion on the evolution of sub-contracting in Japan and elsewhere, with strengthening of decentralized production and consumption, thanks to new breakthroughs in technologies, underlines the inevitability of outsourcing in all industries. A major benefit of the growing power of IT is its capacity to aggregate and integrate solutions emerging from a number of players in the ecosystem. It is true that without the Internet, service outsourcing would have been impossible where delivery had to be either assembled or coordinated. It is inevitable also because globalization is a political reality and with the support of an enabling technological environment, the process can only accelerate. Besides, the growing clout of commercial interests over ideological myths will prevent any repealing of this process.

Yet another reality is the growing level of competition in any sphere. This means that firms have to be innovative not only to address changing customer needs but also to keep the costs down. This is possible only 
if many of the value elements are located/relocated at low cost regions without affecting other success parameters. The Internet has opened up new possibilities on this front and the current debate originates from the ability of countries such as India, otherwise considered poor in terms of infrastructure, to exploit such opportunities.

In other words, what we are witnessing in the form of some resistance, particularly in the US, is the outcome of a shock. It will disappear under three possible situations. One, firms realizing the need to do so for maintaining competitiveness putting counter pressure on the US administration. Two, the federal and state governments in the US playing a losing game for a while but realizing the futility of it, as it happened with the import of Japanese products in the 1970s and '80s and is now happening with the Chinese. Third, the US economy bouncing back and unemployment rates falling giving clear indications of a revival and fading of the threat perception prevailing now.

Drawing on the evolution of the sub-contracting system, we find a variety of possible ownership and relationship structures evolving for the BPOs. As shown in Figure 1, the core value adding activities are always retained within the firm leaving the totally peripheral to be sub-contracted.

The BPO arms of the major Indian IT firms undertake mostly non-core functions of their parents. A number of independent large call centres (under the ITenabled services) also belong to the non-core areas. However, firms such as Texas Instruments, Microsoft, and GE have their own development centres in India that add value to the parents' core value links. The exclusive

Figure 1: Ownership Structure in Sub-Contracting and BPO - Basic Model

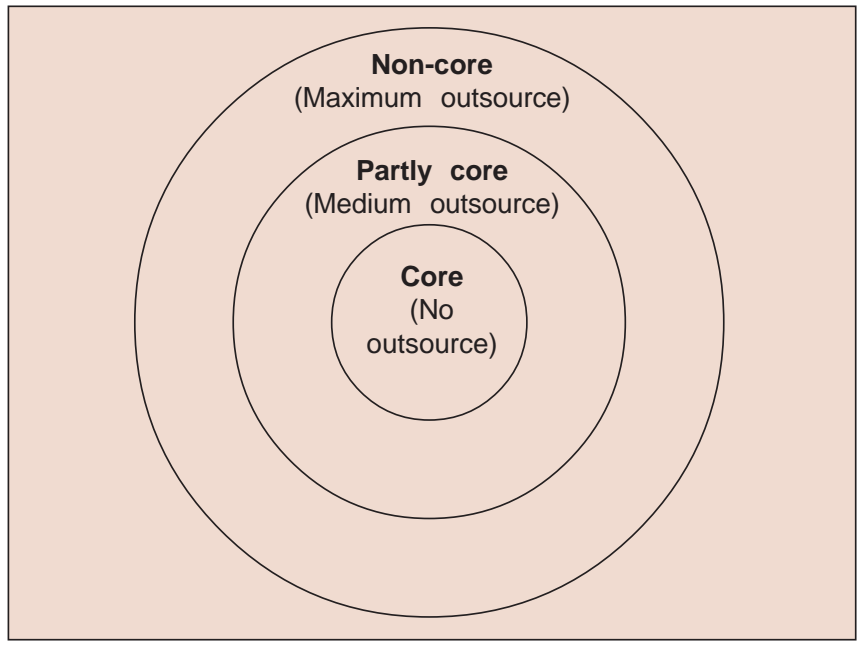

venture divisions that companies such as GE and Ford have created with the IT majors and the equity partnership that some MNCs have with Indian private firms are in essence precursors to formal joint ventures for partly core activities. There are exceptions such as HSBC and Dell Computers that have their own exclusive call centres. Are they non-core? Apparently so, but in reality, at least for both these firms, these are major customer pain relieving points, with significant brand implications, influencing their decision to have own captive facilities. In essence, the definition of core includes not only whether the dollar cost is high but also long-term impact on customer value for the organization.

Some of the factors that come in the way of parents setting up their own operations in India that have significant implications for the growth trajectory of Indian BPOs are:

- direct cost of operations and scale economies

- long-term assessment of India as a low cost centre

- cost-benefit assessment of own vs rented

- brand implications of perceived drop in quality

- robustness of existing systems and processes.

There are also hassle-causing factors including socio-cultural factors such as work ethic in the other organizations to be interacted with. All these suggest that fully owned BPOs may not be set up by many MNCs in India, at least in the near future. The question is, why should they if they can manage it otherwise?

However, given the political pressures under which many of the MNCs operate, the likelihood of more of the value added but not very core activities outsourced while some of the real non-core not outsourced cannot be ruled out since that fulfills drop in job loss in the parent firms' country (say, the US). Since the BPO concept at different levels starting with ITES has been proven and the quality of intellectual manpower in India is found to be excellent in a number of domains including pharma and engineering, there is likely to be growth in outsourcing activities in the partly core areas. This will not only be politically correct but economically attractive for the overseas firms. Simultaneously, these firms will know the intellectual quality of the manpower available in India that can undertake the 'partly core' activities with substantial savings in cost. These are likely to be joint ventures. This also means that some of the BD activities as per Table 2 could be taken up by these joint ventures. 
The key condition for this to happen is the existence of robust systems and processes in the sub-contractors along with adequate domain knowledge and assured physical infrastructure. The parent firms should feel comfortable and confident of treating their sub-contractors as their partners in progress as it happened in the Japanese manufacturing sub-contracting. This is not easy and firms with strong systems and processes stand to gain.

The current turbulence in the $\mathrm{BPO}$ space has to be analysed keeping the above perspectives in mind. While the industry is growing at a breath-taking speed, there are concerns about BPO firms suffering from high levels of manpower attrition at the middle and senior management levels, bandwidth availability to cope with future growth, quality of infrastructure support, and price under-cutting as is normal in an industry with low entry barriers. Many firms do not seem to realize the possible exit barriers and strategies to manage exit, if necessary. What happened in the dot com era can very well happen in the BPO space also unless care is taken to manage this rapid growth while retaining productivity and quality.

\section{Strategic Options}

Outsourcing also represents certain risks to the parent firm. Many BPO managers are concerned about a possible loss of control over their transactions and confidentiality and security of the data if an outsider handles them. From the ITES point of view, outsourcing of business processes and functions to firms in another faraway country heightens risk-perception, and client acquisition for the ITES firm becomes a major task in itself. The basic role of business development function in an ITES value chain is to assure the principal of the quality of service (and thus mitigate risk). The chal- lenges and capabilities of this value link (BD capabilities) are, as discussed earlier, different from the execution capabilities (Ops).The Government of India, in order to allay these concerns, is now considering legislation to bolster the legal framework. All transactions that can have serious effects on customer sales or relations have to be evaluated carefully before they are outsourced. That concern aside, however, many outsourcing arrangements actually provide better performance measures than the in-house systems. This works even in case of off-shore captive BPO units.

It is clear from the above discussion and Table 3 that the classification (functional or organizational) of businesses in the Indian ITES arena into BD-space and operations-space depending on the capabilities developed and residing in any firm is a strong pointer to its performance (in terms of returns, growth, and market scope) and even its likely survival (in terms of minimum viable size required). The cases of the call-centres (both outbound ITES operations players) demonstrate the size imperative and the inherent tendency to move towards the space that offers better returns (namely the BD function in either its pure or hybrid forms) (Annexure).

\section{Impact of Growing Competition}

At the bottom rungs of the ITES value ladder (e.g., 'data entry and conversion' and 'rule set processing'), Ops involves low discretion, high labour 'sweatshop' activity, with little need for any vertical focus. The principal criterion outsourcing firms ('clients') apply here would be savings in operating costs which translates into pricing pressure (Antonucci and Tucker, 1998). Since technological entry barriers are few, the pure Ops players who occupy this space will soon see an oversupply in the market and lowering of prices.

\section{Table 3: Capability Comparison}

\begin{tabular}{|c|c|c|c|}
\hline & $\mathrm{BCC}$ & FCC & GHSL \\
\hline Operations capability & $\begin{array}{l}\text { Pure operations player } \\
\text { Well-developed execution } \\
\text { abilities } \\
\text { Expansion plans on anvil }\end{array}$ & $\begin{array}{l}\text { Pure operations player } \\
\text { at present } \\
\text { Software company } \\
\text { parentage }\end{array}$ & $\begin{array}{l}\text { BD+operations player in the } \\
\text { process of acquiring Ops } \\
\text { capabilities }\end{array}$ \\
\hline BD capability & $\begin{array}{l}\text { Deals only with intermediaries, } \\
\text { brokers, and client's } \\
\text { marketing representatives }\end{array}$ & $\begin{array}{l}\text { At present deals only with } \\
\text { intermediaries but is looking at } \\
\text { developing BD capability and } \\
\text { expanding into inbound BPO }\end{array}$ & $\begin{array}{l}\text { Fairly well-developed } \mathrm{BD} \\
\text { capabilities, leveraging, reputation, } \\
\text { brand image, and past record to } \\
\text { attract business }\end{array}$ \\
\hline
\end{tabular}


We believe that this scenario is likely to continue for some more time since entry barriers are (relatively) low, the market appears attractive with rapid growth, and exit barriers are high (owing to durable and specialized assets invested in). The capital required to set up a medium size 108-seater call-centre facility would be about US\$180,000 worth of upfront investment; though this is a sizable amount for an entrepreneur to invest in the Indian context, many start with a smaller capacity with plans to ramp up fast. High exit barriers can create an over-supply leading to price under-cutting by firms attempting to survive somehow.

There are parallels to such a development in other industries as well - The Indian software industry saw a glut of supply during the heady technology boom years and was saddled with excess capacity immediately after the crash. Then began the inevitable downward pricing pressure from clients leading to a shakeout affecting the smallest players the worst. The resultant price pressure is faced not only by third party BPO service providers but also increasingly by captive BPO units.

The time to reach this shakeout depends on the trade-off struck by the 'client' between financial benefits, technological feasibility, extent of confidentiality and criticality, and political pressures. It is possible for some mid-size firms to acquire small firms and reach a decent size. Large firms may not do so unless there are special benefits.

All the three cases discussed in the Annexure are on an aggressive expansion spree. They consider 300500 seat facility as minimum efficient size. Besides, such firms are acquisition targets with greater bargaining power vis-à-vis buyers and can easily build and maintain redundancies in assets and labour. Clients naturally want to partner with financially stable Ops players, at least with an assurance that the Ops player would continue to be in business for the length of the project. Bigger size helps build credibility in this regard and can be taken as an important signal criterion (Porter, 1985).

The outbound call-centre industry is working capital-intensive and industry insiders estimate a minimum of three months of working capital required to run this business relatively smoothly without financial jolts. Small firms face more problems than big firms in such an unstable scenario as they rely on fewer clients and any default or delay in payments by any of these clients would hit them hard. It does seem likely that all extant serious players in this sector are looking to ramp up capacity. Those that cannot must count on exiting the business as their small size in the Ops area makes business development that much more difficult and therefore the business unviable in commercial terms.

When a firm outsources processes it used to perform in-house, it in effect creates an 'extended organization' where traditional firm boundaries, stretched across separate business entities for the performance of a single function, begin to blur. Though this brings with it cost advantages and opportunities, the extended organizational form also has its share of challenges and risks. It is for this reason that demonstrated execution competence in service providers would rank high on any outsourcer's agenda. Through close contacts and networking, service providers are able to assess and address the concerns of their clients, provide credible assurances, and mitigate risk to a greater extent than would have been possible in the absence of close-knit business relationships.

The top-management view of all the firms profiled is that in a vast majority of cases, pre-existing relationships with the client, contacts within the client firm, and firm presence onsite with at least its marketing representatives and liaison offices there help broach new business opportunities. Therefore, networking abilities and relationships are critical success factors for pure BD players.

Large corporations that set up ITES business tend to build physical infrastructure (either through fresh capital investments, e.g., Reliance Infocom's upcoming facility at Vashi or through acquisitions, e.g., WiproSpectramind) with their own marketing and sales networks - using personal contacts and client relationships developed from their other businesses and set up liaison offices in target countries (chiefly the US and the UK). Many large Indian BPO firms have set up overseas arms for exclusive BD work. Thus, they attempt to straddle both the BD and Ops positions in the ITES value chain.

Simultaneously, many big western consulting majors such as Accenture have entered the $\mathrm{BD}$ and Ops arena in a big way (Forbes, 2002). Accenture's India Solutions Centre near Mumbai is a separate entity though fully owned by Accenture. Indian software firms branching into ITES services also maintain a separate functional and often a separate legal entity for their ITES arm. We have seen that the BD function, aided by intangibles such as personal contacts and networking, is harder to estab- 
lish and hence has its margins protected. Operations, on the other hand, will increasingly go the computer hardware way - commoditized with falling prices. ITES firms in the BD + Ops space, therefore, will seek to focus management time and attention more on developing further the BD function than they will on operations. There would be no incentive to keep operations completely in-house and as part of the same business entity. The imperative for $\mathrm{BD}+$ Ops players then would be to hive off operations as a separate business entity, part of which may also be sold in the public equities market while focusing exclusively on BD. This will enable them to have differential salary structure and organizational facilities in order to keep the cost structure of operations low and keeping the options of taking advantage of transfer pricing possibilities. Also, the critical success factors of these are different.

The two call-centres have been attempting to bypass as many layers of BD intermediaries as they can. This is because clients, aware that the risks of outsourcing are high, are increasingly looking for firms which demonstrate adequate, if not deep, understanding of the client's industry. There are a number of layers of firms existing between the outsourcer and outsourcee who broker the deals, the one closest to the outsourcer doing the BD function. This reflects knowledge deficiencies and is part of the evolution of the industry. As the ITES industry in India grows and matures, the numerous layers of intermediaries would become too unwieldy to be viable. Improved awareness about outsourcers and outsourcees will bring them together, thanks to the Internet and better communication facilities. End-user clients too would get more comfortable in dealing with at most one or two BD players who in turn would negotiate relatively stable business with pure operations firms that would attain minimum critical size. Patni Computer Systems acquired The Reference Inc., a 44employee Boston financial services IT firm with offices in Boston to build up its financial services outsourcing business. We believe such vertical expertise will form an important criterion for BD players looking to acquire business from clients. Further, such expertise may heighten entry barriers into the BD field.

Most large software firms have set up their ITES arm taking advantage of their client contacts abroad and sharing some similarities in the required skills. Some of them are likely to employ more people than their parent firm (e.g., MSource, the BPO arm of Mphasis BFL).
Considering that $\mathrm{BD}$ is a more difficult-to-establish and difficult-to-replicate function than operations and ITES operations share similarities with software execution competencies, most software firms entering ITES are likely to occupy the $\mathrm{BD}+\mathrm{Ops}$ space.

To conclude, the Indian ITES industry is likely to undergo major structural changes in the near future. Successful firms will focus on specific quadrants as shown in Figure 2. There are three major strategic options available to any serious player. The four quadrants represent positions a firm could occupy in the ITES market. After examining the characteristics of each of the quadrants, we delineate our view of the market's evolving future.

Most small players are likely to enter either Quadrant 1 (Q1) or Quadrant $2(\mathrm{Q} 2)$. Their survival chances are negligible in Q1 since this is the position serviced by pure Ops players in Quadrant 4 (Q4) with high Ops and low BD capabilities. These players are likely to try to move towards the High BD-High Ops space in Quadrant 3 (Q3) by developing some vertical expertise and expanding to minimum efficient size of operations. Firms which are unable to achieve either minimum viable size or development of strong BD capability will get caught in an oversupply-low margin-commodity situation and we postulate that most will perish. For the players which do manage the transition successfully to a High BD-High Ops position (Q3), the next logical step in firm evolution would be to strengthen the more profitable and less amenable to commoditization of $\mathrm{BD}$ capability. Large corporate players (especially the established software firms) are likely to enter this space directly by leveraging past client relationships for their

\section{Figure 2: Emerging BD-Ops Structure}

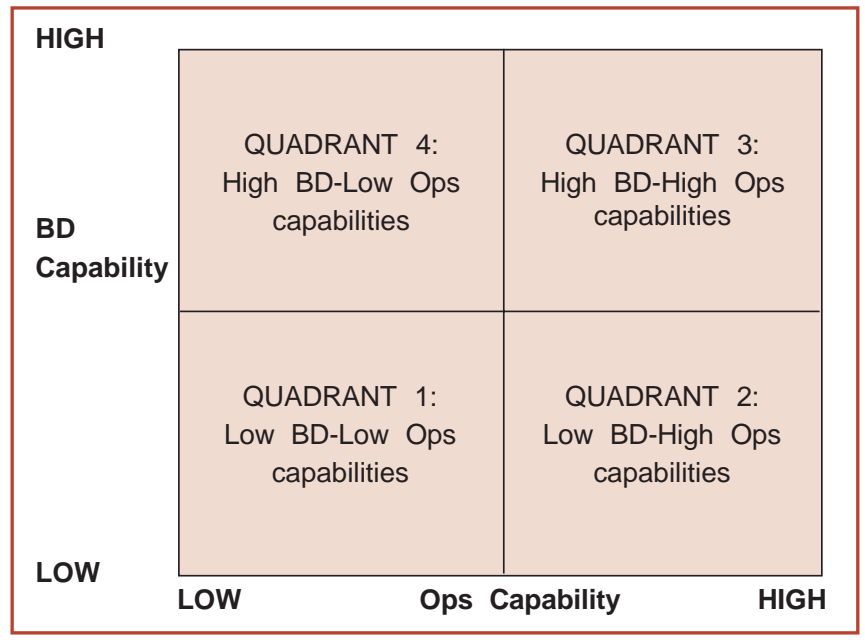

BUSINESS PROCESS OUTSOURCING (BPO) 
BD capability. They may build their Ops capabilities to critical size on entry itself either by constructing greenfield facilities (as was done by Infosys and Satyam Computers) or by acquiring Ops players (Wipro acquiring Spectramind) leading to market consolidation at this level.

We have further postulated that all the players occupying Q3 will have an inherent tendency to keep Ops and BD separate and move towards the Pure BD position (Q4) by either hiving off or otherwise distancing their Ops arms from the BD. Separate entities here imply a functional segregation of the two arms that have different cost and activity drivers even though technically the two arms may yet be part of one legal entity at least for a while. The capitulate Ops-based firms will be in Q4 and are likely to improve their operational capabilities to earn further through efficiency improvements. The same applies to third party players which add value to their clients by bringing additional Opsbased insights and efficiency building option. It may not be wise for any one to start in a very small way if they aim to remain pure Ops players. The future of the market, thus, seems to favour equilibrium positions in Quadrants 2 and 4 (pure BD and pure Ops respectively). Though there will always be some firms in Q3, they will always be under pressure to split their arms and move them into Quadrants 2 and 4.

These arguments have to be seen in the context of our earlier discussion on the theory of the firm. To recapitulate, efficiencies in relative transactions and production costs create opportunities for new firms. In a rapidly changing world where each link on the value chain is increasingly becoming complex requiring specialized expertise, it is natural for them to develop independent personalities. The arguments for Ops and $\mathrm{BD}$ to possess characteristics of independent business divisions from a product-market angle (Ansoff, 1965) are stronger under such circumstances. In order to build and retain the relevant critical success factors, Ops and BD divisions are likely to be kept separate.

The possibilities of desegregation in an economic sense have been heightened by the combination of a number of factors. The most important among them is the Internet, the operating gift of the $20^{\text {th }}$ century to mankind. Recent introduction of a number of ERP products shows promising signs for further remote desegregation and subsequent virtual value creation while ensuring major transaction cost efficiencies; these are witnessing a paradigm shift in the value creation process in manufacturing services.

Such advantages are possible only when production cost efficiencies exist simultaneously. Locations such as India have demonstrated that a combination of cost and quality advantages would move value links there for both Ops and BDs. Further, disaggregation of Ops and BDs is likely to happen with further advances emerging on the Internet and digitization technologies front. The fundamental point is the extent to which constraints that come in the way of flow of resources can be eliminated according to changing balance of demand and supply and resultant bargaining power. The Internet is the creator of a new paradigm.

\section{CONCLUSION}

Organizational competitiveness is determined by its ability to meet changing customer needs better than others. In a society changing rapidly under the influence of a number of socio-techno-economic factors, it is almost impossible for any one organization to build competitiveness on all the value links. We were used to a less than perfect situation. However, new paradigms created by the Internet and several physical infrastructural components have opened up new possibilities for redefining value networks. There is every indication that distances are shrinking across the globe, both in virtual and physical terms, if we look at it from the angle of time, which is the scarcest resource. Further evolution of the outsourcing paradigm will be built on this premise. A synthesis of the pyramidal model of subcontracting and horizontal networks is likely to emerge and the role of the parent organization will be to integrate and synergize as per customer specification. What happened in the manufacturing sector over the years will be true in service industries also thanks to the technological revolution. This is particularly so in services where face-to-face service delivery is either not required or desired by customers for reasons of convenience and cost advantages.

The successful segregation of value elements in a number of processes has enabled value configuration in as many ways as required by customers, both in the case of product and service components of customer value. The current trend in outsourcing will go up when such analysis-synthesis becomes a routine. This will be accelerated also because the capabilities required to do so depend not only on technical skills and knowledge in 
a domain but also strong process capabilities.

The rapidly emerging scenario has multiple implications for the Indian BPOs in general. Since political compulsions often overtake techno-economic logic, and economies of developed nations are still in a recessionary phase, preserving jobs at any cost is an attractive slogan for them, particularly in an election year. Hence, processes that involve substantial job losses are not likely to be outsourced en masse unless the firms are desperate to do so for reasons of survival.

The process may slow down, but the trend cannot be reversed. Indian pure Ops players are likely to face some slowdown in further growth from the same parent, in the short term. It is useful for them to develop a broader client base as far as possible within the US or other western economies for possible growth.

In any case, the Indian BPO firms have to consistently prove their capabilities to deliver and create near indispensable situation for the parent to survive without them. This will not only involve growing technical and domain expertise but also refinement in systems and practices while keeping costs under control. In essence, BPO firms have to manage their consolidation and growth challenges simultaneously.

\section{Annexure: Analyses of Select Cases}

\section{Case Study I: International Call-Centre (ICC)}

ICC, set up in 1999, is a 48-seater facility for telemarketing 'campaigns' for western clients and interfaces with the clients' marketing representatives in India or intermediaries further downstream for getting business.

The cash cycle of the business, though smooth in theory, is actually quite thorny in practice. Working capital requirements come to around USD 1,200-1,500 a month. Marketing at the call-centre takes the form of relationship building and management with the intermediaries who hand out the contracts, and so particular attention is paid to the selection, recruitment, and training of call-centre operators.

The owner of the company has noticed that smaller, weaker players were badly hit by credit shocks, crippling working capital shortages and a dearth of investment. He believes that the path forward is to develop credible expertise in focus areas. He cites financial services as a possible focus area as (i) it provides a logical next step for his firm to step up on the value chain from telemarketing services and (ii) is amenable to remote offshore outsourcing.

\section{Case Study II: First Call-Centre (FCC)}

FCC, started in 2001, is a 48-seater call-centre in the outbound telemarketing area. According to the CEO of the firm, a client's principal concerns are quality, reliability, and cost, not always in that order of priority. The emphasis on quality makes the HR policies of the firm particularly important. Srini, the CEO, identified one of the success factors as hands-on management by the promoter/owner and manager (the other key success factors being transparent and clear systems and processes, quality orientation, and interest in building relationships). The company views intermediaries as an inevitable part of the business and affirms that relationship building skills are necessary for success. The company has not gone for quality certification such as Customer Operations Performance Centre Certification as it was too expensive for them (at USD 70,000 for the assessment and determination of certification suitability). Only a handful of venture capital funded contact-centres in India have this certification currently. Srini admitted that such certification would definitely help in procuring 'better' clients and rates.

According to Srini, repeat-business in a particular area does yield a small learning curve benefit in that errors are fewer the second time and sale rates may typically be higher. But, the high employee turnover rate puts paid to any significant benefits being realized from this. Since every time new business comes in,-product specific training needs to be repeated, outbound telemarketing does not really offer any benefit to specializing into any industry vertical. Having said that, FCC itself is looking into the possibility of specializing in the financial services ITES vertical post-expansion.
The marketing function is handled by the parent firm's marketing liaison office in the US. The company is open to longterm contracts on inbound ITES contracts including e-mail response, live chats, and technical help desk once the planned expansion is completed. So far, no inbound ITES contract negotiations have materialized.

The company keeps nearly three months of working capital ready in the bank because even though most payment cycles span 45 days, collections are erratic. Srini believes that this is typical for almost all similar-sized firms in this business.

Case Study III: Global Health Street Limited (GHSL)

GHSL, a subsidiary of a large multi-speciality hospital, was incorporated in 1999 and aims at providing technology solutions to global healthcare industry. GHSL has several arms providing everything from telemedicine services, distance healthcare education services (Medvarsity), institutional solutions to corporate clients and insurers (Emedlife), IT solutions in healthcare (in partnership with Wipro), health risk assessment services (lifestyle unit) and IT-enabled services within the healthcare vertical. GHSL offers services such as medical billing and coding, account follow up and cash recovery, denial audits and appeals, and patient eligibility verification covering all patient types and payer types.

GHSL seems to believe that size is critical for operations heavy firms. The CEO says that though GHSL is open to accepting medical transcription contracts, it is not a priority area. GHSL believes that medical transcription is a low-value, short-term activity, which in turn may possibly be sub-contracted to a third party under its watchful supervision. The company is looking to leverage its reputation in Asia and its credentials in the healthcare sector to bag lucrative, long-term inbound ITES contracts. GHSL has a marketing liaison office in the US, manned by American marketing executives, and is looking at the US and the UK as big potential markets. Its facilities are on their way to completion.

GHSL has partnered with Wipro Infotech Limited for end-toend IT solutions in the healthcare vertical, GE Medical Systems Ltd. in co-developing doctor's clinic management software, NIIT in its distance healthcare education foray, and Rediff.com, WorldSpace, and Aventis Pharma.

\section{Analysis of ICC and FCC}

For both the call-centres, neither capital nor technology seems to have been an obstacle. Both started with a focus on building pure operations capability - constructing facilities and infrastructure. When both started in 2000-01, the prevalent model for getting contact-centre business for small firms was to approach marketing intermediaries who had telemarketing campaign contracts to give and both followed this. 
Both call-centres are looking at ramping up capacity in an effort to gain critical size. Both are engaged in attempts to move up the value chain in terms of FVC and both are attempting to set up a direct line to the end-user client hoping to bypass the layers of intermediaries. Both believe that there is not much to gain by specializing into verticals at their current scale of operations but are looking towards a vertical focus in the finance space postexpansion into the inbound ITES segment. Both are clear that the horizontal market-space in which they currently operate would be preserved to take on any project they may get outside their vertical.

It is important to note that these intermediaries represent the pure BD segment in our classification. The bargaining power of callcentres vis-à-vis buyers (in this case the intermediaries and further up the chain end-user clients) is extremely low. These small callcentres set up by local entrepreneurs are held hostage by the various layers of intermediaries between the call-centre that actually executes the contract and the client who issues the contract. These intermediaries are typically marketing representatives or subrepresentatives of the client (their need to have specific industry knowledge for success is discussed later). The billing paid for by the client too is routed through this long-winding route and many a time the call-centre puts up with payment delays and ends up getting a meagre portion of expected revenues. There is a need to scale up operations to take advantage of scale economies both in terms of cost and bargaining power. The initial rush of entrepreneurs, lured by the promise of high returns, into the call-centre business created excess capacity in the industry and prices automatically came under pressure.

As far as the risk perception of west-based clients is concerned, utilizing the services of such Indian call-centres for outbound telemarketing jobs seems to be a win-win deal for them. The client would be able to realize drastically lower costs (than if the same job were done in the west) and also completely de-risk his payouts since payments are made only on a commission per sale basis. So even if the call-centre failed to make any sale, the client would lose nothing as payment is only for confirmed sales made.

On the other end, for the call-centres, it is a classic chickenand-egg situation. They would have to commit capital, invest in infrastructure and technology, pay staff salaries and other operating costs, and get the call-centre up-and-running first. Only then could they even pitch for business. Business, as and when it does come, is of the short-term job/project-based variety, which would exhaust itself after a few weeks or months. This, again, underlines the significance of size in the survival and growth of firms in the sector.

\section{Analysis of GHSL}

This firm in its initial actions and in its strategic intent fits our definitional classification of a BD+Ops player. GHSL has first set up a US marketing liaison office. The focus here is on leveraging the established brand name of Global Hospitals Group (as India's leading corporate healthcare service provider) in the healthcare vertical and bag inbound ITES contracts while simultaneously developing the necessary infrastructure or managing leased/partners' facilities to begin business from. GHSL has acquired in-house the high value, discretion-requiring expertise required for its ITES activities (high FVC) while it is in turn likely to manage and supervise (another form of sub-contracting out the operations facilities and infrastructure) the low discretion requiring healthcare ITES work from either its own or partners' facilities. Extremely low FVC work like medical transcription is not on GHSL's active agenda.

\section{REFERENCES}

Alchian, A A and Demsetz, H (1972). "Production, Information Costs and Economic Organization," American Economic Review, 62(5), December, 777-795.

Ansoff, H I (1965). Corporate Strategy, New York: McGrawHill.

Antonucci, Y L and Tucker III, J J (1998). "IT Outsourcing: Current Trends, Benefits, and Risks," Information Strategy: The Executive's Journal, 14(2), 16-26.

Armour, S and Kessler, M (2003). "USA's New Moneysaving Export: White-collar Jobs," USA Today, August 5.

Barreyre, P Y (1988). “The Concept of Impartition Policies: A Different Approach to Vertical Integration Strategies," Strategic Management, 9(5), September-October, 507-520.

Coase, R H (1937). "The Nature of the Firm," Economica, 4(16), November, 386-405.

Gilbert, F W; Young, J A and O'Neal, C R (1994). “BuyerSeller Relationships in Just-In-Time Purchasing Environments,"Journal of Business Research, 29(2), February, 111-120.

Economist (2001). "Business Special: Back Office to the World," 359(8220), May 5, 59, London edition.

Klein, B; Crawford, R G and Alchian, A A (1978). "Vertical Integration, Appropriable Rents and Competitive Contract Process," Journal of Law E Economics, 21(2), October, 297-326.

Magretta, J (1998). "Fast, Global, and Entrepreneurial: Supply Chain Management, Hong Kong Style: An Interview with Victor Fung," Harvard Business Review, 76(5),102-114.
Miwa, Y and Ramseyer, J M (2000). "Rethinking Relationship-Specific Investments: Subcontracting in the Japanese Automobile Industry," CIRJE-F-70, CIRJE, Faculty of Economies, University of Tokyo, http:// ideas.repec.org/p/tky/fseres/2000cf70.html

Morris, J and Imrie, R (1993). "Japanese Style Subcontracting - Its Impact on European Industries," Long Range Planning, 26(4), August, 53-58.

NASSCOM (2004). Strategic Review - 2004, New Delhi: National Association of Software and Services Companies.

Nishiguchi, T (1994). Strategic Industrial Sourcing: The Japanese Advantage, New York: Oxford University Press.

Nishiguchi, T and Brookfield, J (1997). "The Evolution of Japanese Subcontracting," MIT Sloan Management Review, 39(1), Fall, 89-101.

Prahalad, C K and Hamel, Gary (1994). Competing for the Future, Massachusetts: Harvard Business School Press.

Porter, M E (1980). Competitive Strategy: Techniques for Analyzing Industries and Competitors, New York: Free Press.

Porter, M E (1985). Competitive Advantage: Creating and Sustaining Superior Performance, New York: Free Press.

Porter, M E (1996). "What is Strategy?" Harvard Business Review, 74(6), November-December, 61-78.

Rumelt, R (1974). Strategy Structure and Economic Performance, Boston: Harvard University Press.

Schoenberger, R J (1982). Japanese Manufacturing Techniques, New York: Free Press.

Taylor, C R and Wiggins, S N (1997). "Competition or 
Compensation: Supplier Incentives under the American and Japanese Subcontracting Systems," The American Economic Review, 87(4), September, 598-618.

Webster, M; Muhlemann, A P and Alder, C (2000).

"Decision Support for the Scheduling of Subcontract

Manufacture," International Journal of Operations and

Production Management, 20(10), 1218-1235.

Weston, J F; Chung, K S and Hoag, S E (1990). Mergers,

K Ramachandran is Professor of Entrepreneurship and Strategy at Indian School of Business, Hyderabad. He has a Ph.D. from the Cranfield University, UK and was on the faculty at Indian Institute of Management, Ahmedabad for 16 years. He has published in the areas of entrepreneurship and strategy with special interests in opportunity spotting, resource building strategies of mid-sized firms, and family enterprises. He is the founding General Secretary of the Society of Entrepreneurship Educators.

e-mail: k_ramachandran@isb.edu
Restructuring $\mathcal{E}$ Corporate Control, Englewood Cliffs, New Jersey: Prentice Hall.

Williamson, O E (1971). "The Vertical Integration of Production: Market Failure Considerations," The American Economic Review, 61(2), May, 112-123.

Williamson, O E (1973). "Markets and Hierarchies: Some Elementary Considerations," The American Economic Review, 63(2), May, 316-325.

Sudhir Voleti is a Doctoral Student in Marketing at the Simon School of Business, University of Rochester, USA. He did his B.Tech. from the Birla Institute of Technology and PGDM from Indian Institute of Management, Calcutta. He worked with Accenture as a consultant and the ICFAI Business School as faculty before joining the Ph.D. programme. His areas of interest include strategic marketing, BPO, and corporate strategy. e-mail: voleti@simon.rochester.edu

To the man with an ear for verbal delicacies - the man who searches painfully for the perfect word, and puts the way of saying a thing above the thing said - there is in writing the constant joy of sudden discovery, of happy accident.

Henry Louis Mencken 